\title{
o live cinema e o cinema interativo: uma análise a partir do filme Ressaca
}

Resumo

Neste artigo, é apresentada uma análise de Ressaca (2008), de Bruno Vianna, filme que tem como proposta a montagem ao vivo. Inserindo o filme no contexto do live cinema e aproximando-o do cinema interativo, busca-se entender os processos de escrita do roteiro, montagem e relação com o espectador. Como método, são utilizadas entrevistas com espectadores e com o diretor do filme, além de pesquisa bibliográfica.

Palavras-chave:

Ressaca, interatividade, live cinema 


\section{Live cinema and interactive cinema: an analysis from Hangover}

\section{Abstract}

In this paper, an analysis of Hangover (2008), movie by Bruno Vianna, is presented. The film's main characteristic is the live edition. Inserting it in the context of live cinema and bringing it closer to interactive cinema, we try to understand the process of scriptwriting, edition and its relation with the audience. As method, interviews with the audience and with the director are used, besides bibliographical research. 


\section{Introdução}

"Um longa-metragem. Um quebra-cabeça. Um jogo da amarelinha." Essas três frases compõem a página inicial do site de Ressaca (2008), filme de Bruno Vianna, e resumem o que provavelmente é a sua essência: um longa-metragem que não tem fim nem começo, que propõe um caminho sempre diferente a ser trilhado. Protagonizado por João Pedro Zappa, o longa relata a adolescência de Thiago, que tenta crescer e descobrir a vida no meio de uma tormenta política, econômica e familiar. Trata-se do Brasil no final da década de 80 e início da de 9o, período de bastante confusão política e econômica. O quebra-cabeça vivido pelo personagem central se potencializa com a proposta experimental de montagem simultânea à exibição. Através de uma interface visível ao público chamada de "Engrenagem", o diretor ou um montador que tenha suficiente conhecimento sobre as cenas seleciona e ordena as partes que serão exibidas em cada sessão, tornando cada uma delas única.

Vianna atua no cinema há mais de quinze anos, tendo em sua filmografia quatro curtas e dois longas-metragens. Ele leva ao extremo, nesse projeto, uma ideia que havia sido iniciada em Cafuné (2005), seu longa-metragem de estreia. O filme foi lançado em circuito comercial com mais de um final, além de ter suas partes disponibilizadas para download, um convite ao espectador para que ele fizesse outra montagem. Ambas estratégias já demonstram uma proposta de fazer um cinema mais colaborativo, com maior interferência do espectador. Em Ressaca, essa proposta se expande, pois, além do público interferir nas escolhas do diretor na exibição, as possibilidades não se restringem a dois ou três finais, mas são infinitas. Em depoimento no site de Ressaca, Vianna fala sobre o processo criativo: 
Mas o projeto só tomou forma mesmo depois do Cafuné e a experiência que fiz de lançar diversas versões do filme no cinema e distribuí-lo por copyleft na internet. É que ao editar o filme eu percebi que não gostaria de amarrar a história e sim comunicar às pessoas que elas podiam interpretá-lo de diversas maneiras ou até levar isso ao pé da letra e reeditá-lo, fazendo sua própria versão. Depois disso me dei conta que o Ressaca faria muito mais sentido assim, com uma estrutura não-linear, onde coisas podiam acontecer duas vezes, não acontecer, ter outros desenlaces, etc. Por isso quis avançar mais a idéia de fazer um filme recombinável, como "Jogo da Amarelinha", de Cortázar e outras obras não lineares. $(2008$, p.2)

Vianna cita OJogo da Amarelinha, de Julio Cortázar, como referência para seu trabalho. De fato, a proposta do livro é dar maior poder ao leitor, que pode seguir uma das duas ordens de capítulos sugeridas pelo autor ou lê-lo na ordem em que desejar. Essa referência segue ainda para o plano narrativo: uma das personagens principais se chama Maga, mesmo nome de personagem do livro de Cortázar.

No cinema de narrativa clássica, o significado dado pelo artista à obra está finalizado e o resultado que chega ao espectador é rígido, pois mesmo considerando que o espectador empresta seus próprios significados ao filme, o resultado físico dele é sempre o mesmo. Porém, em propostas como a de Ressaca, transforma-se a relação entre obra, artista e público, pois o montador passa a ter um papel fundamental na exibição, assim como o público, que, mesmo não participando de forma ativa, acaba influenciando o artista. Há um diálogo criativo que é renovado a cada exibição, nunca se esgotando.

Ressaca situa-se dentro do conceito de Live Cinema e possui fortes características interativas. Segundo a definição dada pelos organizadores da Mostra Live Cinema, “(...) hoje o termo 'LIVE CINEMA' diz respeito à execução simultânea de sons e imagens por artistas visuais que apresentam suas obras ao vivo diante dos espectadores.". Já o cinema interativo caracteriza-se por permitir uma forte participação do usuário (espectador), seja diretamente, quando ele decide o rumo da obra ou faz uso de alguma interface para se comunicar com ela, ou indiretamente, como em Ressaca, em que o público influencia o diretor em certos aspectos.

O live cinema e o cinema interativo têm uma trajetória bastante recente no Brasil. A Mostra Live Cinema, que ocorre desde 2005 no Rio de Janeiro, é a única dedicada especial- 
mente a esses tipos de projetos no país. Entretanto, Ressaca e outros filmes com proposta interativa - como A Gruta (Filipe Gontijo, 2008) - começam a achar espaço dentro de festivais já consagrados, como o Festival do Rio, onde Ressaca foi exibido, e em mostras alternativas.

Apesar de ser uma prática ainda pouco comum e consideravelmente nova, o live cinema e o cinema interativo têm seu crescimento baseado principalmente nas mídias digitais, que aumentam de forma significativa as possibilidades de interação com o filme, de maneira ainda pouco pensada.

Buscou-se estreitar a pesquisa, delimitando o objeto de estudo e, portanto, fazendo uma análise de caso do filme Ressaca. Para uma análise mais eficaz, serão utilizados três métodos: pesquisa bibliográfica, essencial a basicamente qualquer tipo de estudo acadêmico, observação direta e entrevistas.

Através da pesquisa bibliográfica, serão revisados os conceitos de "cinema digital", "live cinema" e "cinema interativo", evidenciando as relações existentes entre eles e ressaltando suas principais características. Para isso, serão utilizados estudos sobre o digital como uma nova linguagem, especialmente em relação ao cinema, de Lev Manovich, os de Alex Primo e os de Glorianna Davenport (e do grupo Interactive Cinema Group do MIT) sobre cinema interativo. Além disso, Vincent Amiel servirá como base para a análise fílmica, destacando a narrativa e a montagem.

A observação direta se faz válida pela experiência que presenciamos na exibição do filme no Festival CineEsquemaNovo de 2009. Certos aspectos técnicos e de condições de exibição ficam mais claros, além de trazer uma outra perspectiva da obra como espectadores.

E, enfim, para entendermos de forma mais concreta a relação entre público e filme e até fazer correção e esclarecimento de questões e hipóteses levantadas durante o processo de pesquisa, foi realizado um estudo de recepção, que se baseará nas respostas de seis pessoas que assistiram ao filme Ressaca. $\mathrm{O}$ diretor Bruno Vianna também respondeu a perguntas enviadas por e-mail e suas respostas fecham lacunas que anteriormente estavam em aberto.

\section{Live cinema e cinema interativo}

De “teatro filmado" à arte com linguagem própria, o cinema já passou por múltiplas revoluções, desde os seus primórdios. A invenção de tecnologias várias vezes teve papel fundamental 
na criação de novos elementos na linguagem cinematográfica. Podemos destacar a chegada do cinema falado, o vídeo, novos e leves meios de captação de áudio em campo (em relação ao documentário), o digital e a tecnologia 3-D, entre outros.

Neste artigo, temos especial interesse no digital, cuja definição é bastante controversa, como poderá ser visto mais adiante. Lev Manovich o define como "um caso particular de animação que usa filmagem live action como um de seus vários elementos" (2001, p.255). Essa definição, embora extremamente aberta, parece se referir mais a filmes cujos cenários, objetos e, às vezes, até personagens, são criados em computador (como exemplo, temos filmes como os novos episódios da série Star Wars e Avatar). Porém, neste estudo, adotaremos o termo "cinema digital" como um produto audiovisual que utiliza-se de meios digitais (calculados em forma binária, segundo Manovich) em algum estágio de sua produção, seja na gravação, na edição ou na exibição.

O live cinema, já definido na introdução desse trabalho, é uma das novas formas de pensar o cinema possibilitadas pelo digital. Mia Makela o diferencia do cinema clássico por não ter uma narrativa linear e por não ser normalmente baseado no trabalho de atores ou nos diálogos. "A situação 'ao vivo' impõe suas necessidades, mas também clama por liberdade do cinema com estrutura linear" (MAKELA, 2010, p.1). A não-linearidade, exemplificada por filmes como Um Cão Andaluz (Un chien andalou, Luis Buñuel, 1928), Pulp Fiction (Quentin Tarantino, 1994) e Amnésia (Memento, Christopher Nolan, 1994), figura, assim, como uma qualidade essencial, ou quase, do live cinema.

O live cinema aproxima-se bastante, em conceito, do VJ'ing, sendo elas duas das três abordagens do audiovisual ao vivo, segundo David Fodel (a outra é a visual music). A definição do autor do termo é "O VJ'ing engloba aquelas atividades de performance audiovisual, que tipicamente são realizadas em clubes noturnos, onde o foco da audiência muda constantemente e a intenção da performance é o acompanhamento da música ou pano de fundo para o contexto social" (2010, p.4). Mia Makela complementa a definição ao dizer que o trabalho do $V J$ se diferencia do trabalho do artista do live cinema pelo fato de que o primeiro não produz o seu material, trabalhando em cima de material alheio, enquanto que o segundo, em geral, o produz. Além disso, ao voltarmos à definição de Fodel, podemos perceber a ênfase dada ao local da performance, deixando claro que a atenção do espectador não está voltada para ela. 
Por ser ao vivo e, portanto, único, o live cinema possui uma característica performática. Cada exibição só será vista daquela maneira naquela única vez (a não ser, obviamente, que alguma delas seja gravada). Lembramos, então, da discussão da “aura da irreprodutibilidade técnica” de Walter Benjamin. O espectador sabe que aquela obra será perdida assim que a sessão terminar, que os elementos utilizados provavelmente nunca mais serão dispostos exatamente daquela mesma maneira. Mia Makela fala sobre a experiência do espectador:

Ver o criador apresentar seu trabalho é diferente de assistir a um filme: existe a possibilidade de feedback instantâneo de ambas as direções. O contexto live impõe as possibilidades de participação da audiência. Além disso, a maioria das performances não são documentadas. Elas viram momentos partilhados entre o artista e a audiência, únicos e difíceis de repetir. (2010, p.5)

O diálogo artista-público é, portanto, um elemento essencial no live cinema. E a partir desse ponto, traça-se uma ponte entre o live cinema e o cinema interativo, já que a principal proposta desse último é a participação do espectador.

"Interativo" refere-se a toda mídia em que o usuário pode fazer escolhas de elementos ou caminhos a seguir. $\mathrm{O}$ trabalho interativo tende a ser único, assim como o trabalho live. Para Martins, “(...) quando falamos de cinema digital interativo, estamos tratando de um produto híbrido (MANOVICH), que remete ao tradicional (linguagem e estrutura narrativa) e a utilização das novas tecnologias resultando num novo produto."(2010, p.4). Os exemplos de interatividade vão desde textos com links na internet até jogos complexos em que o usuário entra no papel de um dos personagens, tendo liberdade para explorar o cenário.

Para Alex Primo, o termo "interatividade" é "impreciso e escorregadio" (2007, p. 12) e, na maioria das abordagens, se limita a uma definição puramente tecnicista, colocando em segundo plano a recepção da informação pelos interagentes. Ele cita Lucien Sfez, que acredita que a palavra "interativo" vem acompanhada de um deslumbramento e serve como argumento de venda de ideias. Para Sfez, existe a impressão de uma real expressão do interagente. "Crê-se estar na expressão imediata, espontânea, onde reina soberana a representação. Delírio. Creio exprimir o mundo, esse mundo de máquinas 
que me representam e que, na verdade se exprimem em meu lugar." (apud PRIMO, p. 52). Porém, Primo defende que não se trata de limitar o que é interatividade, mas sim de diferenciar os tipos de interação qualitativamente. Discutiremos sua classificação mais adiante.

A noção de interatividade nas artes - e principalmente no cinema - há anos é idealizada como uma maneira de fugir das narrativas tradicionais e de dar poder ao espectador. Manovich acredita que a interatividade sempre esteve presente em diversas formas de arte, já que elas demandam do público que ele preencha as lacunas e busque, em seu próprio referencial, maneiras de entender a obra. Ele cita elipses na narrativa literária, a manipulação do foco da atenção do espectador no cinema, na pintura e no teatro, a montagem no cinema, que une partes sem qualquer ligação e dá um novo sentido a elas, entre outros.

Porém, o "interativo" passou a ser uma característica das novas mídias e, segundo o mesmo Manovich, "Uma vez que o objeto é representado em um computador, ele automaticamente se torna interativo" (2001, p. 71). Para Denis Renó, "A interatividade é uma característica nata do usuário digital, que espera participar de todo o processo, expressando desejos e decisões" (2010, p. 7). Para ele, esse usuário está acostumado a fazer múltiplas tarefas ao mesmo tempo, tornando-se "multimídia". Assim, torna-se natural a aproximação desse tipo de usuário com o cinema interativo.

Então, esse usuário quer ter poder sobre o conteúdo que irá consumir, seguindo o pensamento de Manovich, que diz que “(...) a lógica dos novos meios corresponde à lógica da distribuição pós-industrial de 'produção sob demanda' e 'na hora"' (2001, p.56). Se antes havia uma tendência à massificação, hoje observa-se o contrário: o conteúdo se encaixa dentro das necessidades de cada usuário. Se o discurso, antes, era “Todos são iguais", hoje ele é "Você é especial" (ou pelo menos procura-se dar essa impressão).

Voltando à classificação de Primo, há dois tipos de interatividade, quando há a mediação de um computador: a mútua e a reativa. A primeira, como o nome já diz, é compartilhada por mais de um interagente e se baseia na relação interpessoal. Trata-se de uma interação que constantemente muda seus parâmetros e que não pode ser prevista. Como exemplos, programas de bate-papo virtual e listas de discussão. Já a interatividade reativa é caracterizada por uma unilateralidade na relação, não sendo uma interatividade construída por dois interagentes. 
As possibilidades de interação são pré-definidas por alguém, finitas e não há possibilidade de sair dessas opções.

As formas de interação são constantemente renovadas e com a chegada da televisão digital, espera-se que o aumento do controle do usuário seja considerável, com links direcionando para mais informações sobre o assunto, para lista de produtos e para, de fato, interferências na narrativa.

Para Manovich, que parece ser um pessimista em relação ao assunto, essas mídias não são de fato interativas, pois elas, na verdade, seguem o fluxo mental de outra pessoa, como ele explica no seguinte trecho:

Antes, nós leríamos uma frase de uma história ou uma linha de um poema e pensaríamos em outras linhas, imagens, memórias. Agora, a mídia interativa nos pede que cliquemos em frases sublinhadas para irmos para outra frase. Resumindo, nós somos convidados a seguir associações objetivamente existentes, pré-programadas. Posto timidamente, no que podemos ler como uma versão renovada do conceito do filósofo francês Louis Althusser de 'interpelação', nós somos convidados a confundir a estrutura mental de outra pessoa pela nossa própria. (2001, p.74)

Para Massou, o interativo tem um "caráter incompleto" (o que podemos relacionar também com o live cinema): "O espectador verá apenas uma parte da imagem, uma das formas possíveis dessa imagem, mas raramente a totalidade. A imagem interactiva é, pois, fundamentalmente <<incompleta >>, como sublinha Jean-Louis Weissber: mostra apenas um estado num momento $<<t>>$ da sua exibição no ecrã." (2008, p. 210)

Uma questão interessante de ser discutida dentro do cinema interativo é a da autoria. Há uma valorização muito grande do papel do espectador e, assim, passa a ponderar-se quem é o real autor da obra. É possível argumentar que a obra só é completa se, de fato, manifesta-se seu poder interativo. Porém, para Martins, esse não é um ponto tão problemático, pois ela acredita que os caminhos a serem seguidos sempre serão pré-determinados pelo diretor, de acordo com sua vontade e criatividade. Primo admite que o espectador de um filme convencional difere do de um filme interativo, porém ele reforça a ideia de Martins, afirmando que a participação do espectador tem limitações e, por isso, descarta a ideia de uma autoria dividida. 
Em ambas modalidades de cinema apresenta-se a questão da não-comercialidade. No live cinema, por conta da obrigatoriedade da presença do performer, esse é um ponto bastante óbvio. Afinal, fica impossível uma distribuição em grande escala. Já no cinema interativo, a criação e instalação de interfaces e aparelhagens em salas ao redor do mundo significariam um enorme gasto. Além de um gasto maior na produção, pois para cada parte diferente, mais material deve ser produzido, gerando mais custo. Portanto, o live cinema, em sua essência, é um tipo de cinema que não pretende chegar ao mainstream. Já o cinema interativo continua como uma aposta. Lançando mão do exemplo do cinema $3-\mathrm{D}$, percebemos que seus grandes empecilhos eram basicamente os mesmos do cinema interativo: tecnologia, viabilidade econômica e criação de conteúdo. Porém, percebe-se que, superados os problemas tecnológicos, o cinema $3 \mathrm{D}$ emplacou nas salas, transformando-se, inclusive, na grande aposta dos estúdios tradicionais como forma de chamar o público aos cinemas.

\section{Ressaca}

As exibições do filme acontecem da seguinte maneira: o diretor permanece entre o público e a tela de exibição, em algum lugar que não atrapalhe o público, mas que evidencie a presença sua e da "Engrenagem", manipulando a ordem das imagens. Além dele, um músico "performa" a trilha musical do filme (embora a sessão do CEN- CineEsquemaNovo, em Porto Alegre, não tenha contado com a presença do músico.). No total, são 129 cenas e três horas e vinte minutos de material, resultando em, normalmente, de uma hora e vinte minutos a duas horas de exibição. A quantidade grande de cenas é justamente o que dá a maleabilidade do filme: quanto mais cenas, mais possibilidades de resultados diferentes.

A interface utilizada para a edição de Ressaca, batizada de "Engrenagem", foi desenvolvida especialmente para o uso do filme por Maíra Sala e consiste em uma tela transparente de acrílico sensível ao toque, que permite ao manipulador visualizar e escolher as sequências a serem exibidas. Essas sequências, que ficam separadas dentro de círculos (cada um contem cenas de uma temática especial, de escolha do montador) podem ser organizadas e reorganizadas a qualquer instante. O material, que já é pré-editado, pode ser acrescido de transições e de planos de outras sequências, além da possibili- 
dade de cortar planos e de mais de uma pessoa manipular esse material, já que a tela é multi toque.

Maíra Sala, em artigo sobre a "Engrenagem", discute a presença da interface em relação à imersão da plateia. A presença do diretor na frente dos espectadores com uma interface tão grande pode ser considerada distrativa e até desnecessária, afinal, um computador laptop poderia substituir a "Engrenagem". Ao mesmo tempo em que a sala de cinema induz a que o espectador entre completamente no filme e permaneça atento a ele, a interface o puxa de volta, evidenciando seu processo de construção. India Mara Martins chama isso de "o potencial antiilusionista" do cinema interativo e, sobre isso, Robert Stam fala que "Enquanto a arte ilusionista procura causar a impressão de uma coerência espaço-temporal, a arte antiilusionista procura ressaltar as brechas, os furos e as ligaduras do tecido narrativo. Os modos de descontinuidade variam de era para era, de gênero para gênero. Mas descontinuidade em si está sempre presente (...).” (apud MARTINS, p. 8). Sala diz que essa questão foi bastante ponderada durante o processo de criação e gera uma dicotomia interessante sobre a participação do espectador, retomando "uma certa tradição dos cinemas novos, que se inspiravam no 'estranhamento' ou 'efeito de distanciamento' de Brecht e desejavam que o espectador tivesse uma atitude ativa diante do que era exibido na tela." (MARTINS, 2010. p. 2). Sobre a presença da aparelhagem, Michael Lew fala:

O outro problema, familiar aos músicos eletrônicos, está em usar o laptop como um instrumento. Durante nossos shows, a maioria dos membros não-especialistas da platéia não entendeu o papel do performer no palco. Nós concluímos que a interface precisa ser: transparente, porque a platéia quer ver o processo. Ela quer ver as ações do performer e entender o que está acontecendo por trás da cena; e performática, de forma que a platéia possa se engajar no esforço do performer e perceber como isso está ligado às imagens e aos sons produzidos. (2004, p. 3)

A interface, então, é um elemento essencial do live cinema e do cinema interativo e pensar a narrativa deslocada da interface não faz sentido num trabalho desses. "E é a interface da obra que cria sua materialidade única e a experiência de usuário única. Mudar a interface mesmo remotamente seria mudar dramaticamente a obra." (MANOVICH, 2001, p.78) 
Outro importante ponto a ser discutido refere-se à narrativa. O cinema clássico preocupa-se em esconder sua estrutura do espectador, através de diversos artifícios, entre eles a linearidade, que tem no raccord um de seus principais truques. Como já citado no capítulo anterior, a não-linearidade é uma das características mais marcantes do live cinema, e a maioria dos trabalhos feitos dentro da proposta do live cinema se distanciam um pouco do cinema de narrativa tradicional e se aproximam da vídeo arte e das vídeo performances. Porém, como o release de Ressaca diz no seu primeiro parágrafo "Ressaca pretende ser um longa-metragem no limite entre o cinema e o espetáculo ao vivo, partindo do ponto em que param os VJs que fazem performances ao som de música eletrônica com vídeos pré-gravados.”. Há uma clara intenção narrativa. E estabelecido isso, como se engloba o conceito do live cinema de maneira que ainda sobre uma história?

Analisando a narrativa de Ressaca, percebe-se que há uma certa individualidade em cada cena. Como explica Bruno Vianna, "As cenas são pensadas individualmente e dentro do conjunto. A partir do momento em que o roteiro passou a ser escrito pensando-se nessa estrutura, passamos a desenvolver cenas que tivessem relação com outras cenas, porém mantendo certa independência...

Indo além do roteiro, a construção da narrativa está intimamente ligada à montagem, afinal, o Efeito Kuleshov mostra-se particularmente com efeito aqui. Se uma sequência, sozinha, quer dizer A e outra quer dizer B, juntas, elas podem ter inúmeros significados, dependendo da percepção de cada espectador. E, assim, criam-se novos significados a cada montagem feita. Além disso, não há um sentido de causa e efeito. Nas exibições, nota-se que um mesmo evento pode acontecer mais de uma vez, com desfechos diferentes. Por exemplo, o pai do personagem principal, na exibição referida aqui, morreu três vezes, todas de maneiras diferentes. Outras situações podem nem acontecer em algumas exibições. Vincent Amiel sustenta:

Para que haja consciência da narrativa, é preciso que o espectador esteja em presença de uma continuidade, que ele sinta o elo entre os diferentes planos que a planificação estabeleceu. É a primeira característica, por definição pouco visível e sobretudo não manifesta, de uma montagem clássica: estabelecer essas continuidades, de espaço, tempo e sensações. (2008, p. 37) 
Marie-Laure Ryan analisa a narrativa interativa: "Simplesmente não é possível construir uma história coerente de todas permutações de um grupo de fragmentos textuais, porque fragmentos são implicitamente ordenados por relações de pressupostos lógicos, causalidade material e sequência temporal." (apud JONES, 2010. p. 8)

Obviamente, Ressaca não se trata de uma obra com montagem clássica. Mas, se a proposta continua sendo a de ter uma linha narrativa, a leitura do espectador fica bastante modificada. Bruno Vianna foi questionado sobre a construção da narrativa de forma a não perder o interesse do espectador e respondeu: “(...) as cenas têm diferentes tons dramáticos. Assim, a questão de não perder o interesse do espectador é resolvida pela construção dramática que se faz na hora da edição, em que tento (em geral) criar um arco narrativo que prenda a atenção das pessoas."

Ao mesmo tempo, é interessante analisar a resposta do diretor à pergunta "No momento da exibição, as cenas são organizadas por blocos temáticos? Se sim, você segue algum tipo de ordem por bloco ou você monta sem ter qualquer tipo de guia pré-determinado?”. Ele diz que, apesar de não seguir nenhum guia, certos fatores o influenciam. Citaremos alguns desses fatores mais adiante.

\section{Diálogos em torno da obra}

Há vários tipos de diálogo em Ressaca: o de Bruno Vianna com a obra, o de Bruno Vianna com o músico, e o dos dois com a plateia. O processo então conta com dois regentes, o diretor e o músico, cada um com poder para agir dentro da sua esfera. Quando perguntado sobre o grau de liberdade do músico, Bruno afirmou que ele tem autonomia para criar, interferindo na construção do sentido da cena e até levando Vianna a se adaptar à música interpretada. Ele ainda informa que os dois, às vezes, conversam durante a exibição, dando indicações e sugerindo ações.

O diálogo de Vianna com a obra é mediado por diversos fatores que vão desde o seu humor até a boa receptividade ou não do público. Em entrevista, o diretor afirmou que pode se "viciar" em certos blocos, trazendo-os várias vezes na mesma sequência (Cena A- Cena B- Cena C), e que ele também cria uma expectativa do público. "Um público mais cinéfilo pode provocar um filme menos linear, um público mais popular pode provocar um filme mais 'novela'." 
Porém, nesse estudo vamos nos deter mais no diálogo diretor-obra-espectador, que é transformado na proposta de Ressaca. Para compreender melhor as diferentes formas como o público absorve o filme, uma amostragem de espectadores foi entrevistada em busca de, ao menos, esclarecer algumas questões levantadas durante a pesquisa sobre o live cinema.

O universo do estudo realizado compreende as respostas de seis pessoas, escolhidas por estarem presentes na exibição referida de Ressaca. É importante destacar que elas todas, na época do festival CineEsquemaNovo, estavam participando de uma Oficina de Crítica Cinematográfica e, portanto, são espectadores com um certo grau de conhecimento da natureza cinematográfica. Embora uma exibição com um grupo heterogêneo de pessoas fosse o ideal, se tornaria bastante complicada a organização desse evento, pela exigência da presença do diretor. Entretanto, as respostas dadas pelo grupo se mostraram elucidativas e atuam de forma a auxiliar para uma melhor compreensão do tema trabalhado nesse artigo e no entendimento do espectador de trabalhos como Ressaca, sem darem qualquer tipo de resposta definitiva às questões. A opção por nomear os entrevistados apenas por letras foi feita considerando que apresentar o nome e profissão deles não é relevante ao estudo. As entrevistas foram realizadas via e-mail, individualmente, e eram compostas por seis perguntas:

- Questão 1: Você considera que a ação do montador e a presença da interface são objetos de distração do público?

- Questão 2: Você sentiu que a reação do público poderia realmente influenciar na decisão do montador? Você sente que a interatividade foi limitada? Se sua resposta for positiva na última pergunta, como você acha que a interatividade poderia ser mais eficaz?

- Questão 3: A característica única de cada exibição fez com que você se interessasse mais pelo filme?

- Questão 4: O que mais lhe chamou atenção no filme?

- Questão 5: A falta de linearidade confundiu você dentro da narrativa?

- Questão 6: Você já sabia da proposta da montagem do filme quando entrou na sala de cinema? Você considera que isso tenha mudado sua percepção do filme?

Optou-se pela entrevista semi-estruturada, que permite aos entrevistados maior amplitude nas respostas. Embora 
as perguntas aceitem simples respostas de "Sim" ou "Não", a grande maioria das pessoas ouvidas foi além e desenvolveu uma argumentação.

As respostas à questão 1 sugeriram o que já havia sido comentado anteriormente: a interface e a presença do diretor são fatores de distração. Embora um entrevistado tenha dito que não foi distraído, os outros afirmaram ou que sim ou que é relativo, dependendo da construção, mais ou menos interessante, do filme. O entrevistado D acredita que essa distração faz parte do experimento e afirmou "Acho correto ver o filme não simplesmente como um filme, mas quase como uma instalação, em que a obra em si é composta não apenas do que está na tela, mas também da própria figura do diretor e do seu equipamento.". Há a noção de que o que está sendo exibido é mais do que um filme, mas uma performance. Já outro entrevistado, o B, afirma que "A aparelhagem é extremamente exótica e o método por si só passa a chamar mais atenção do que o filme propriamente dito.".

A questão 2, sobre o grau de influência que o público poderia ter sobre o diretor, também teve respostas divididas. Três entrevistados acreditam que sim, a reação do público influenciava no resultado do filme, enquanto os outros três pensam que não há interatividade. Dentre os que não acreditam que exista interatividade no processo, o entrevistado B respondeu "(...) apenas me senti voyeur do processo de montagem solitário do Bruno Vianna." e os outros dois afirmaram que tiveram a impressão de que as decisões do diretor eram definidas previamente, deixando a margem de improviso para pequenas porções. Nota-se um certo ceticismo em relação à abertura do processo.

Em relação ainda à pergunta 2, o entrevistado $\mathrm{D}$ levantou uma questão interessante com a afirmação "A decisão do autor é soberana. Diferentemente do livro O Jogo da Amarelinha, do Cortázar, que é uma referência bastante óbvia, o espírito e as próprias decisões do espectador importam muito pouco. (...) A vontade do autor importa mais do que a vontade do público.”. Entretanto, ele acredita que esse não é um defeito do projeto, sendo da natureza de sua proposta.

Na questão 3, houve unanimidade: todos os entrevistados acreditam que a característica única de cada exibição fez com que eles se interessassem mais pelo filme, porém o entrevistado $\mathrm{B}$ afirmou que, embora inicialmente ele tenha se interessado pela proposta do projeto, após a exibição, ele mudou de ideia e imagina que "(...) o filme cresceria muito sem esse dispositivo.". 
Os dois aspectos citados como os que mais chamaram a atenção dos entrevistados (questão 4) foram o roteiro e a natureza única do projeto.

Todos foram unânimes em afirmar que a falta de linearidade não atrapalhou na compreensão do filme, embora um entrevistado tenha afirmado que, em momentos, ela pode sim confundir (questão 5). O entrevistado D, que presenciou duas exibições, ressaltou, porém, que essa não-linearidade varia de sessão para sessão, tornando o filme mais eficaz ou não.

A pergunta 6 , acrescentada à lista para ver em que grau o conhecimento prévio da proposta do filme mudaria a percepção do mesmo, fica comprometida com a escolha dos entrevistados. Como mencionado antes, eles são todos pessoas participantes do festival, logo, todos sabiam de antemão o que seria exibido. Mas, de qualquer maneira, nota-se que, com exceção do entrevistado C, todos concordam que o fato de eles já terem conhecimento sobre o filme muda, sim, a forma como eles o recebem. "Talvez a gente superestime as imagens que vê, o filme em si, exatamente porque está diante de algo que não é restrito a apenas aquilo que está vendo na tela- exatamente porque está vivendo uma experiência que não está restrita à narrativa em si.", reflete o entrevistado D.

\section{Conclusão}

O interesse pelas mídias interativas aumenta cada vez mais com a expansão do uso da internet e com a chegada da TV digital. As melhorias tecnológicas também estimulam cada vez mais experimentos com montagem e outros elementos "ao vivo".

Ressaca não se coloca para o espectador como um filme interativo e em nenhum momento se faz menção à palavra "interatividade" no site do projeto. Porém, pelos fatores explicados ao longo do artigo, o espectador pode influenciar no rumo da obra durante sua exibição. Entretanto, apesar do contato diretor-público, as possibilidades de interação são pré-definidas pelo diretor, assim como os possíveis resultados. Trata-se, portanto, de uma obra com interatividade reativa, segundo os conceitos de Primo. Mas essa influência se mistura com outros fatores (humor do diretor, "vício" de montagem, local da exibição) e, desse modo, talvez não seja forte o bastante para se discutir uma real interatividade no trabalho. Embora o diretor tenha explicitado que a reação da platéia pode alterar a sequência de imagens, os próprios espectadores 
pensam na questão com bastante ceticismo, acreditando que a opinião soberana é a de Bruno Vianna.

Entretanto, essa pequena parcela de interatividade não diminui o projeto e sua proposta, já que a participação do espectador não era um de seus fundamentos e que a principal meta é a montagem live. Observa-se uma proposta crescente de abertura do processo de montagem na filmografia do diretor Bruno Vianna, que talvez no futuro, leve a algum experimento mais voltado à participação efetiva e determinante do público.

\section{Referências Bibliográficas}

AUMONT, Jacques et all. A estética do filme. 6a edição. São Paulo: Papirus, 2008.

BENJAMIN, Walter. A Obra de arte na época de sua reprodutibilidade Técnica. Teoria da Cultura de Massa. Paz e Terra, 2010.

BENTES, Ivana. Vídeo e Cinema: rupturas, reações e hibridismo in Made in Brasil. Três décadas do vídeo brasileiro. MACHADO, Arlindo (org.). São Paulo: Itaú Cultural, 2003. p. $113-132$

CORTÁZAR, Julio. O jogo da amarelinha. $15^{\mathrm{a}}$ edição. Rio de Janeiro: Civilização Brasileira, 2009.

DAVENPORT, Glorianna. My storyteller knows me: the challenge of interactive narrative. Conference Proceedings of IDATE Conference: Investing in the Digital Image Personal and Interactive Television. 1993. p. 516-520.

DAVENPORT, Glorianna. BRADLEY, Brian. Everyone's Cinema: Towards the future of cinematics. Oberhausen Film Festival. 1997.

DAVENPORT, Glorianna. 1001 Electronic Story Nights: Interactivity and the Language of Storytelling. Disponivel em: $<$ http://mf.media.mit.edu/pubs/conference/10o1Electronic. pdf> Acesso em: 18/10/2010.

FODEL, David. Live Cinema: Context and Liveness. Disponível em: <http://www.davidfodel.com/research/Fodel_ Live_Cinema.pdf > Acesso em: 20/10/2010.

GALYEAN, Tinsley A. Narrative Guidance of Interactivity. Cambridge: Massachussets Institute of Technology, 1995. Tese (doutorado em Filosofia).

GARDIES, René (org.). Compreender o cinema e as imagens. $1^{\underline{a}}$ edição. Lisboa: Edições Texto \& Grafia, 2008. 
JONES, Adrian. Creating a user interface for interactive environments: with a focus on interactive cinema. Disponível em: <http://www.novuscom.net/ ajones/industrial/research/Docs/InterfaceNavigation.pdf> Acesso em: 18/10/2010. JONES, Adrian. Meaning and the Interactive Narrative: In the context of Object-Oriented Interactive Cinema. Disponível em: <http://www.novuscom.net/ ajones/industrial/research/Docs/InteractiveNarrative.pdf> Acesso em: 18/10/2010.

LEW, Michael. Live Cinema: Designing an instrument for cinema editing as a live performance. Proceedings of the 2004 Conference on new interfaces for musical expression. Hamamatsu, 2004.

MAKELA, Mia. The practice of live cinema. 2008. Disponível em: <http://ww.solu.orgtext_PracticeOfLiveCinema.pdf> Acesso em: 17/10/2010.

MANOVICH, Lev. The language of new media. Cambridge: Massachussets Institute of Technology, 2001.

MARTINS, India Mara. Cinema interativo e seu potencial antiilusionista. Disponível em: <http://www.users.rdc.puc-rio.br/imago/site/narrativa/producao/india-final.pdf> Acesso em: 18/10/2010.

PRIMO, Alex. Interação mediada por computador. $2^{\underline{a}}$ edição. Porto Alegre: Sulina, 2007.

RENÓ, Denis Porto. Narrativa audiovisual: uma possibilidade de interatividade na internet. Intercom- XXX Congresso Brasileiro de Ciências da Comunicação. Santos, 2007.

RENÓ, Denis Porto. A importância do cinema interativo na pós-modernidade. Razon y palabra. Disponível em: <http://www.razonypalabra.org.mx/N/N71/VARIA/20\%20 PORTO_REVISADO.pdf> Acesso em: 18/10/2010.

RENÓ, Denis Porto. GONÇALVES, Elizabeth Moraes. Disponível em: <https://encipecom.metodista.br/mediawiki/images/o/oo/GT3-_o2-_Hipertexto_e_montagens-_ Denis_e_Elisabeth.pdf> Acesso em: 18/10/2010.

SALA, Maíra. El engranaje expuesto: Una herramienta física para edición de películas en directo. Disponível em: $<$ http:// www.geral.etc.br/engranaje/> Acesso em: 18/10/2010.

TEODORO, Maria Luiza. Live-video: Influências e novas perspectivas do audiovisual em tempo-real. Intercom- XXX Congresso Brasileiro de Ciências da Comunicação. Santos, 2007.

VIANNA, Bruno. Depoimento. Release do filme Ressaca para imprensa. Disponível em: <www. ressaca.net $>$ Acesso em: 18/10/2010. 
VIVEIROS, Paulo. Cinema e Tecnologia: novas interacções. Livro de Actas do $4^{\circ}$ SOPCOM. Braga, 2005.

Recebido em: 30/03/2011

Aceito em: 22/o6/2011

\author{
ELEONORA LONER COUTINHO \\ eleonoraloner@yahoo.com.br \\ Eleonora Loner Coutinho é graduada em Cinema e Animação pela \\ Universidade Federal de Pelotas (UFPel). Seu interesse em pesquisas \\ engloba as novas tecnologias, seus usos e a criação de significados a \\ partir delas. Também escreve críticas cinematográficas, publicadas no \\ site da Associação de Críticos de Cinema do Rio Grande do Sul e no site \\ do Festival Manuel Padeiro de Cinema e Animação.
}

